với nhận định của Phạm Hồng Đức [7] cho rằng khu vực động mạch não giữa là khu vực hay gặp nhất vì động mạch não giữa là một động mạch lớn và là nguồn cung cấp máu cho phần lớn bán câu não của hệ tuần hoàn trước.

Trong nghiên cứu của chúng tôi phần lớn các ổ dị dạng võ có từ hai cuống mạch nuôi trở lên $(63,89 \%)$, các ổ dị dạng vỡ thường là những ổ có một tĩnh mạch dẫn lưu duy nhất $(72,2 \%)$ điều này cũng tương tự với các nghiên cứu của nhiều tác giả khác.

Siêu âm Doppler xuyên sọ phát hiện ổ dị dạng có kích thước trung bình và lớn lần lượt là $93,75 \%$ và $100 \%$, trong khi đó với ổ dị dạng có kích thước nhỏ thì tỷ lệ phát hiên thấp hơn với 40,9\%. So sánh tốc độ dòng chảy bên nuôi ổ dị dạng với bên đối diện, chỉ có động mạch não giữa có tốc độ tăng lớn hơn có ý nghĩa thống kê với $p<0,05$. Theo nghiên cứu của Phan Văn Đức [4], tỷ lệ phát hiện AVM qua siêu âm Doppler xuyên sọ trên nhóm có kích thước trung bình và lớn có độ nhạy cao (thấp nhất là $87,5 \%$, cao nhất là $100 \%$ ). Mặt khác, với nhóm kích thước nhỏ tỷ lệ này hạ xuống còn $50 \%$. Kết quả này của chúng tôi cũng tương tự với kết quả của Mast và cộng sự [8] khi nghiên cứu 114 bệnh nhân AVM với siêu âm Doppler xuyên sọ, độ nhạy của tốc độ trung bình và chỉ số mạch lần lượt là $85 \%$ và $63 \%$, khi phân nhóm thì nhóm kích thước trung bình và lớn cũng có độ nhạy khá cao (từ 73 đến 100\%) còn nhóm kích thước nhỏ thì có độ nhạy thấp 39\% và 31\% lần lượt theo tốc độ trung bình và chỉ số mạch.

\section{KẾT LUÂN}

Độ tuổi hay gặp nhất của các bệnh nhân AVM võ là trên 40 tuối, chiếm tỷ lệ 63,9\%; tuổi trung bình $43 \pm 14,7$. Bệnh gặp ở cả hai giới với tỷ lệ nam/nữ là 1,27/1. Động mạch não giữa tham gia cấp máu cho ổ dị dạng chiếm $52,78 \%$. TCD là phương pháp hữu ích để chẩn đoán các dị dạng thông động tĩnh mạch não nó có độ nhạy cao với các AVM có kích thước trung bình và lớn.

\section{TÀI LIÊU THAM KHẢO}

1. Friedlander RM. Arteriovenous malfor- mations of the brain. N Engl J Med 2007; 356:2704-12.

2. Cognard C, Spelle L., and Pierot L. (2004), Pial arteriovenous malformations in: Intracranial vascular malformations and aneurysm, Springer. 39-92.

3. Shaligram S.S., Winkler E., Cooke D. và cộng sư. (2019). Risk factors for hemorrhage of brain arteriovenous malformation. CNS Neurosci Ther, 25(10), 1085-1095.

4. Phan Văn Đức Lê Văn Thính, Hoàng Văn Thuận (2018), siêu âm Doppler xuyên sọ và hình ảnh chụp mach máu não của dị dạng thông độngtĩnh mạch nã̉o.

5. Marco A.Stefani, Phillip J.Porter, et al (2002), Large and deep brain arteriovenous malformation are associated with risk of future hemorrhage, Stroke, 3. 1220.

6. Deruty $\mathbf{R}$, et al (1985), Les malformations Arterio-veineuses Cerebrales, Neurochir, 31. 21-29

7. Pham Hông Đức, Phạm Minh Thông, Lê Văn Thính (2010), Các yếu tố cấu trúc mạch liên quan đến biểu hiên xuất huyết của dị dạng động tĩnh mạch não, Tạp chí Y học thực hành (705) - số 2, 52-55.

8. Mast H, Mohr JP, Osipov A, et al (1995) Steal is an unestablished mechanism for the clinical presentation of cerebral arteriovenous malformations, Stroke, 26. 1215-1220

\title{
KẾT QUẢ SÀNG LỌC SUY GIÁP BẨM SINH TẠI BỆNH VIỆN NHI TRUNG ƯO'NG
}

\section{TÓM TẮT}

Muc tiêu: Đánh giá kết quả sàng lọc suy giáp bẩm sinh tại Bệnh viện Nhi Trung Ương. Đối tượng và phương pháp nghiên cứu: Nghiên cứu đươơ thực hiện trên 159 trẻ em có kết quả lấy máu gót

\section{${ }^{1}$ Trường Đại học Y Hà Nọi, \\ ²Bênh viện Nhi Trung Ương \\ Chịu trách nhiệm chính: Nguyễn Ngọc Khánh \\ Email: dieplan5972@gmail.com \\ Ngày nhận bài: 10.9.2021}

Ngày phản biên khoa họ: 15.10 .2021

Ngày duyệt bài: 11.11.2021

\section{Diệp Thị Thúy Lan', Bùi Phương Thảo²,} Nguyễn Ngọc Khánh ${ }^{2}$, Vũ Chí Dũng ${ }^{2}$

chân của chương trình sàng lọc sau sinh suy giáp trạng bẩm sinh có nồng độ TSH $\geq 10 \mathrm{mUI} / \mathrm{L}$. Kết quả: Tỷ lệ dương tính thật qua lần sàng lọc thứ hai với mẫu máu tĩnh mạch là $78,6 \%$.Tỷ lệ suy giáp vĩnh viễn là $38,2 \%$ và tỷ lệ suy giáp thoáng qua là $60,8 \%$, có sự khác biệt về chỉ số TSH lấy lần đầu tiên, TSH tĩnh mach và Fít tĩnh mạch giữa hai loại suy giáp vĩnh viễn và suy giáp thoáng qua $(p<0,001)$. Kết luận: Tỷ lệ suy giáp bẩm sinh trên đối tượng được sàng lọc trong nghiên cứu của chúng tôi là tương đối cao, bển canh đó tỷ lệ suy giáp vĩnh viễn cần được điều trị kịp thời để giảm thiểu gánh nặng bệnh tật cho bệnh nhi.

Từ khóa: Sàng lọc sơ sinh, Suy giáp bẩm sinh 


\section{SUMMARY \\ SCREENING RESULTS FOR CONGENITAL HYPOTHYROIDISM AT THE VIETNAM \\ NATIONAL CHILDREN'S HOSPITAL}

Objectives: Evaluation of screening results for congenital hypothyroidism at the Vietnam National Children's Hospital. Subjects and methods: The study was conducted on 159 children with heel blood collection results of the postpartum screening program for congenital hypothyroidism with TSH levels 10 $\mathrm{mUI} / \mathrm{L}$. Results: The true positive rate through the second screening with venous blood samples was $78.6 \%$. The rate of permanent hypothyroidism is $38.2 \%$ and the rate of transient hypothyroidism is $60.8 \%$, there is a difference in TSH values obtained at first time, venous TSH and venous FT4 between the two types of permanent hypothyroidism transient and transient hypothyroidism $(p<0.001)$. Conclusions: The rate of congenital hypothyroidism in screened subjects in our study is relatively high, besides the rate of permanent hypothyroidism needs to be treated promptly to minimize the burden of disease for pediatric patients.

Keyword: Newborn screening, Congenital hypothyroidism

\section{I. ĐĂT VẤN ĐỀ}

Suy giáp bẩm sinh là một trong những rối loạn nội tiết hay gặp ở trẻ em và có ảnh hưởng đển một trong số 3000 đến $4000 \mathrm{ca}$ sinh sống trên toàn thế giới[1]. Các báo cáo gần đây cho thấy tỷ lệ nhiểm suy giáp bẩm sinh ngày càng tăng, đặc biệt tỷ lệ mắc suy giáp bẩm sinh ở trẻ sơ sinh châu Á cao hơn các dân tộc khác [2]. Suy giáp bẩm sinh để lại hậu quả nặng nề cho trẻ như tử vong hoặc đần độn suốt đời. Điều này có thể được ngăn ngừa bằng cách phát hiện và điều trị sớm, do đó các chương trình sàng lọc phát hiện suy giáp bẩm sinh trong giai đoạn sơ sinh đã được phát triển vào đâu những năm 1970 và được nhiều nước trên thế giới áp dụng.[3]

Mục đích của các chương trình sàng lọc sơ sinh là phát hiện tất cả các trường hợp mắc bệnh càng sớm càng tốt, với chi phí rẻ nhất và để tránh kết quả dương tính giả. Trong những năm gần đây, các phương pháp tự động và nhạy cảm hơn đã được ứng dụng để xác định cả TSH và T4 trong các mẫu máu khô. Những phương pháp mới này đã tăng độ nhay và độ đặc hiệu trong việc phát hiện suy giáp bẩm sinh.Tại Việt Nam, sàng lọc sơ sinh bắt đâu được thí điểm năm 1999. Tuy chưa có số lượng thống kê tỉ lệ sàng lọc trên toàn quốc nhưng từ năm 2017 đến nay, số lượng bệnh nhân được chẩn đoán suy giáp qua chương trình sàng lọc sơ sinh tại Bệnh viện Nhi Trung ương ngày càng tăng mối năm trung bình 70 - 80 bệnh nhân. Vì vậy nhằm đưa ra các kết quả xác thực nhất về quá trình sàng lọc trẻ mắc suy giáp bẩm sinh chúng tôi thực hiện nghiên cứu này với muc tiêu: "Đánh giá kêt quả sàng lọc suy giáp bẩm sinh tại Bệnh viện Nhi Trung Ưong"

\section{II. ĐỐI TƯỢNG VÀ PHƯƠNG PHÁP NGHIÊN CỨU}

\subsection{Thời gian và địa điểm nghiên cứu}

- Địa điểm nghiên cứu: Khoa Nội tiết Chuyển hoá - Di truyền và Phòng khám Nội tiết, Bệnh viện Nhi Trung Ương.

-Thời gian nghiên cứu: 01/01/2019 $31 / 12 / 2020$

\section{2. Đối tượng nghiên cứu}

- Tiêu chuẩn chọn: Trẻ đếnkhám sàng lọc sau sinh suy giáp trạng bẩm sinh tại khoa Nội tiết - Chuyển hoá - Di truyền và Phòng khám Nội tiết, Bệnh viện Nhi Trung Ương.

- Tiêu chuẩn loại trừ: (1)Cha mẹ người bệnh không đồng ý tham gia nghiên cứu. (2) Trẻ tử vong.

\subsection{Phương pháp nghiên cứu}

Thiết kế nghiên cứu: Mô tả tiến cứu

Cõ̃ mẫu và phương pháp chọn mẫu:

Cỡ mẫu: Áp dụng công thức tính cỡ mẫu cho một tỷ lệ

$$
n=Z^{2}(1-a / 2) \frac{p(1-p)}{(d)^{2}}
$$

n: là cỡ mẫu tối thiểu; $Z_{(1-a / 2)}$ : Hệ số tin cậy (với độ tin cậy $95 \%, z=1,96$ ).

a: Mức ý nghĩa thống kê (sử dụng $a=0,05$ ).

$\mathrm{p}$ : Để đảm bảo cõ̃ mẫu bao phủ các nội dung nghiên cứu chúng tôi lấy giá trị $\mathrm{p}$ theo nghiên cứu của Ashkan Habib và cộng sự với tỷ lệ dương tính thật là $68,4 \%$ với mức sàng lọc ban đầu $\mathrm{TSH} \geq 10 \mathrm{IU} / \mathrm{ml}[4]$

$d$; độ chính xác tương đối (sử dụng $\varepsilon_{=}$ $0,08)$; Từ công thức trên ta tính được cỡ mẫu $n=130$ trẻ em, lấy thêm $10 \%$ đối tượng để đảm bảo cõ mẫu tối thiểu được cõ̃ mấu dự kiến là 143. Trên thực tế chúng tôi thu thập được n=159 đối tượng nghiên cứu.

Phươngpháp chọn mẫu: Nghiên cứu áp dụng phương pháp chọn mẫu thuận tiện, đối tượng đáp ứng tiêu chuẩn lựa chọn đều được đưa vào nghiên cứu

2.4. Quy trình nghiên cứu: Bước 1: lập danh sách người bệnh có kết quả sàng lọc TSH $\geq 10 \mathrm{mUI} / \mathrm{L}$. Bước 2: thu thập thông tin người bệnh. Bước 3: lấy xét nghiệm TSH, FT4 huyết thanh. Bước 4: đánh giá kết quả sàng lọc.

2.5.Quản lý và phân tích số liệu. Số liệu sau khi thu thập được nhập và quản lý bằng phần mềm SPSS 25.0. Các thống kê mô tả và 
phân tích được thực hiện với biến số định tính và định lượng.

2.6. Đạo đức nghiên cứu. Nghiên cứu được tiến hành sau khi được thông qua Hội đồng khoa học và được sự chấp thuận của lãnh đạo Trung tầm Sàng lọc sau sinh và các bệnh hiểm gặp Bệnh viện Nhi Trung Ương. Đối tượng nghiên cứu (ở đây là cha me hoặc người chăm sóc trẻ) hiểu rõ mục tiêu nghiên cứu và tự nguyện tham gia vào nghiên cứu.

\section{KẾT QUẢ NGHIÊN CỨU}

Bảng 3.1. Đặc điểm kêt quả của quá trinh sàng loc lần môt

\begin{tabular}{|c|c|}
\hline Số trẻ được sàng lọc & 79380 \\
\hline Số trẻ sàng lọc dương tính (TSH> $>10)$ & 159 \\
\hline Tỷ lệ sàng lọc dương tính & $0,2 \%$ \\
\hline Tỷ suất sàng lọc dương tính & $1 / 500$ \\
\hline
\end{tabular}

Kết quả sàng lọc cho thấy có tất cả 79380 trẻ sơ sinh được tiến hành sàng loc. Trong đó có 159 trẻ sơ sinh được sàng lọc dương tính, tỷ lệ sàng lọc dương tính là $1 / 500$.

Bảng 3.2. Đăc điếm về kêt quả của quá trinh sàng loc lần hai

\begin{tabular}{|l|l|}
\hline Số trẻ được sàng lọc lần hai & 159 \\
\hline
\end{tabular}

\begin{tabular}{|c|c|}
\hline $\begin{array}{c}\text { Số trẻ được chấn đoán suy } \\
\text { giáp trạng bẩm sinh }\end{array}$ & 125 \\
\hline Tỷ lệ dương tính thật & $125 / 159$ \\
\hline Số trẻ dương tính giả & 34 \\
\hline
\end{tabular}

Kết quả của lần sàng lọc thứ hai với mầu máu tĩnh mạch cho thấy có $100 \%$ đối tượng sau khi được sàng lọc lần 1 được sàng lọc lần 2. Số trẻ được chẩn đoán dương tính là 125, bên cạnh đó số trẻ được chẩn đoán dương tính giả là 34 .

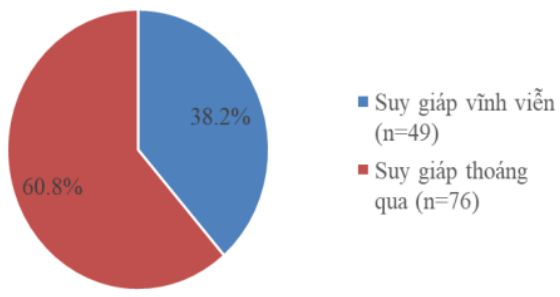

Biểu đồ 3.1. Đặc điểm về loại suy giáp trạng $(n=125)$

Trong số những trẻ được sàng lọc đương tình ở lần thứ hai, có 49/125 trẻ thuộc thể suy giáp vĩnh viễn $(38,2 \%)$ và $60,8 \%$ thuộc thể suy giáp thoáng qua.

Bảng 3.2. Đặc điểm của thể suy giáp với môt số chỉ số xét nghiệm(n=125)

\begin{tabular}{|c|c|c|c|c|}
\hline \multicolumn{2}{|c|}{ Chỉ số xét nghiệm } & $\begin{array}{c}\text { Suy giáp vî́nh viên } \\
(\mathrm{n}=49)\end{array}$ & $\begin{array}{l}\text { Suy giáp thoáng qua } \\
(n=76)\end{array}$ & $\mathbf{p}$ \\
\hline & & $135(98-193,9)$ & $37,5(25,6-71,4)$ & $<0,001^{*}$ \\
\hline TSH & & $473(2$ & 58,7 & $<0$ \\
\hline FT4 máu tĩnh mạch & vi!) & $2,75(1,91-4,2)$ & $12,14(9,33-15,89)$ & $<0,001^{*}$ \\
\hline
\end{tabular}

*Mann whitney test

Kết quả bảng trên cho thấy giá trị trung vị về TSH máu gót chân trong nhóm suy giáp vĩnh viễn (135) là cao hơn so với nhóm suy giáp thoáng qua $(37,5)$, sự khác biêt có ý nghĩa thống kê $(p<0,05)$. Bên cạnh đó, chúng tôi cũng nhận thấy giá trị TSH máu tĩnh mạch cao hơn ở trong nhóm suy giáp vĩnh viễn so với suy giáp thoáng qua $(p<0,05)$. Ngược lại, giá trị trung vị về chỉ số FT4 máu tĩnh mạch trong nhóm suy giáp thoáng qua là cao hơn so với nhóm suy giáp vĩnh viễn $(p<0,05)$.

\section{BÀN LUẬN}

Hormone tuyến giáp đóng một vai trò quan trọng trong sự trưởng thành của não người thông qua sự di chuyển, biệt hóa và tín hiệu của tế bào thần kinh. Tác động quan trọng nhất của hormone tuyến giáp là lên hệ thần kinh trung ương, đặc biệt là trong hai năm đầu đời. Các biểu hiện lâm sàng của suy giáp bẩm sinh khi mới sinh là tương đối nhe và nghi ngờ lâm sàng của bệnh xuất hiện ở dưới $1 \%$ trẻ sơ sinh bị ảnh hưởng. Do đó, việc bỏ sót chẩn đoán SGBS ở trẻ sơ sinh cuối cùng có thể dẫn đến các biến chứng không thể phục hồi, chẳng hạn như điếc hoặc khuyết tật trí tuệ. Vì vậy, cần thiết kế một chương trình sàng lọc để phát hiện suy giáp bẩm sinh trong giai đoạn đầu của bệnh bằng cách đo T4 (thyroxine) hoặc TSH (hormone kích thích tuyến giáp) ở trẻ sơ sinh. Kết quả sàng lọc trong nghiên cứu của chúng tôi thự hiện trên 79380 trẻ, trong đó số trẻ sàng lọc với mẫu máu gót chân cho kết quả dương tính là 159 trẻ chiếm tỷ lệ $0,2 \%(1 / 500$ trẻ). Kết quả này này là thấp hơn so với đo lường lặp lại từ năm 2013 đến năm 2016 của Iran với tỷ suất 1/313,66. Kết quả của chúng tôi tương tự với kết quả nghiên cứu của Razavi Z và cộng sự (2016) 1:446[5], cao hơn so với kết quả sàng học ở Hoa Kỳ với tỷ lệ dương tính là 1:2118.[6] Sự khác biệt về tỷ suất mắc suy giáp bẩm sinh có thể do tình trạng thiếu I-ốt và quan trọng nhất là sự khác biệt trong các phương pháp sàng lọc suy giáp bẩm sinh.Tại Việt Nam ngay từ những năm 1970 đã xây dựng một 
chương trình phòng chống các rối loạn do thiếu iốt, tuy nhiên chương trình này thiếu đi tính bền vững với những hạn chế về kinh phí.

Số trẻ được sàng lọc lần hai là 159 trẻ dương tính trong lần sàng lọc đầu tiên. Trong lần sàng lọc thứ hai, số trẻ được chẩn đoán suy giáp bẩm sinh là 125 người với tỷ lệ dương tính thật là 1:635 và số trẻ được chẩn đoán dương tính giả là 34 trẻ. Trong đó có $38,2 \%$ trẻ bị suy giáp vĩnh viễn và $61,8 \%$ trẻ bị suy giáp thoáng qua. Kết quả này có sự khác biệt với các nghiên cứu của Mahin Hashemipour và cộng sự trên 204 bệnh nhân suy giáp bẩm sinh nguyền phát với tỷ lệ suy giáp vĩnh viễn là $59,8 \%[7]$ và nghiên cứu của Gaudino và cộng sự ở Pháp với tỷ lệ suy giáp thoáng qua và vĩnh viến lần lượt là $38 \%$ và $62 \%$ trong số 79 bệnh nhân.[8] Tỷ lệ suy giáp thoáng qua cao hơn có thể do thiếu iốt, quá tải iốt, truyền qua nhau thai của tự kháng thể ngăn chặn thụ thể thyrotropin (TSH), tăng tự kháng thể tuyến giáp hoặc uống thuốc kháng giáp.

Nghiên cứu của chúng tôi cũng cho thây sự khác biệt về chỉ số TSH lấy lần đầu tiên, TSH tĩnh mạch và FT4 tĩnh mạch giữa hai loại suy giáp vĩnh viễn và suy giáp thoáng qua $(p<0,001)$, kết quả ngày cũng tương đồng với nghiên cứu của tác giả Habib. A và cộng sự (2021)[4]. Ngoài ra nghiên cứu cũng cho thây một số những hạn chế như, mới chỉ dừng lại ở một bệnh viện và cỡ mẫu nhỏ, tính đại diện cho số lượng trẻ sinh ra là còn hạn chế. Quy trình sàng lọc mới chỉ dừng lại ở hai bước, lấy máu gót chẩn và tĩnh mạch nên dễ dẫn đến sai số

\section{KẾT LUẬN}

Tỷ lệ suy giáp bẩm sinh trên đối tượng được sàng lọc trong nghiên cứu của chúng tôi là tương đối cao, bên cạnh đó tỷ lệ suy giáp vĩnh viễn cần được điều trị kịp thời để giảm thiểu gánh nặng bệnh tật cho bệnh nhi

\section{TÀl LIỆU THAM KHẢO}

1. A. Büyükgebiz (2013), "Newborn screening for congenital hypothyroidism", J Clin Res Pediatr Endocrinol, 5 Suppl 1(Suppl 1), tr. 8-12.

2. J. Kopel (2020), "A global perspective on newborn congenital hypothyroidism screening", Proc (Bayl Univ Med Cent), 33(1), tr. 137-139.

3. D. S. Saleh, S. Lawrence, M. T. Geraghty và các cộng sự. (2016), "Prediction of congenital hypothyroidism based on initial screening thyroidstimulating-hormone", BMC Pediatr, 16, tr. 24.

4. A. Habib, A. Shojazadeh, M. Molayemat và các cộng sự. (2021), "Prevalence and predictive factors of transient and permanent congenital hypothyroidism in Fars province, Iran", BMC Pediatr, 21(1), tr. 264.

5. Z. Razavi và L. Mohammadi (2016) "Permanent and Transient Congenital Hypothyroidism in Hamadan West Province of Iran", Int J Endocrinol Metab 14(4), tr. e38256.

6. L. Pitts, W. McCormick và G. J. Mick (2019), "Congenital Hypothyroidism: 8-Year Experience Using 2 Newborn Screens in Alabama", Horm Res Paediatr, 91(5), tr. 319-328.

7. M. Hashemipour, S. Hovsepian, R. Kelishadi và các cộng sự. (2009), "Permanent and transient congenital hypothyroidism in IsfahanIran", J Med Screen, 16(1), tr. 11-6.

8. R. Gaudino, C. Garel, P.' Czernichow và các cộng sứ. (2005), "Proportion of various types of thyroid disorders among newborns with congenital hypothyroidism and normally located gland: a regional cohort study", Clin Endocrinol (Oxf), 62(4), tr. 444-8.

\section{ĐốI CHIẾU ĐĂC ĐIỂM LÂM SÀNG VỚI HÌNH ẢNH NộI SOI VIÊM TAI GIỮA CẤP Ở TRẺ EM TẠI BỆNH VIỆN E TRONG GIAI ĐOẠN NĂM 2019 - 2020}

\section{TÓM TẮT}

\footnotetext{
*Trường Đại học Y Dược, ĐHQGHN

**Bênhh viển E Trung Ương

***Bêenh viện Tré Em Hải Phòng

Chịu trách nhiệm chính: Nguyễn Như Đua

Email: nhuduanguyen@gmail.com

Ngày nhận bài: 7.9.2021

Ngày phản biện khoa học: 27.10.2021

Ngày duyệt băi: 11.11.2021
}

\author{
Nguyễn Như Đua*, Đoàn Thị Hồng Hoa*, \\ Trương Thị Thu Hương**, Bùi Duy Vũ $\tilde{u}^{* * *}$
}

Đặt vấn đề: Viêm tai giữa cấp (VTGC) là tình trạng nhiễm trùng, ứ đọng dịch trong tai giữa. Bệnh thường khởi phát đột ngột trong thời gian ngắn, với các triệu chứng lâm sàng và hình ảnh nội soi liên quan với nhau. Mục tiêu: Đối chiếu đăc điểm lâm sàng với hình ảnh nội soi viêm tai giữa cấp ở trẻ em tai Bênh viện $\mathrm{E}$ trong giai đoạn 2019 - 2020. Đối tượng và Phương pháp nghiên cứu: Nghiên cứu mố tả cắt ngang gồm 40 bệnh nhân dưới 16 tuổi, được chẩn đoán VTGC, được điều trị tại khoa Tai Mũi Họng của Bệnh viện $E$ từ tháng 9/2019 đến 4/2020. Kết quả và 